\title{
The role of Personality, Mood, Subjective Health, and Stress in Depressive Symptoms among High School Students
}

\author{
K. Gunnar Götestam ${ }^{\star, \star \star, \star \star \star}$ \\ Sven Svebak ${ }^{*, * * * *}$ \\ Eva Naper Jensen ${ }^{\star \star \star \star \star}$
}

* Norwegian University of Science and Technology, The Medical Faculty, Trondheim
** St Olaf Hospital, Health Mid-Norway
*** Stanford University, Department of Psychiatry \& Behavioral Medicine
**** The University College of North- Trøndelag, NO-7600 Levanger

***** The County Municipality of SouthTrøndelag, School Division, Trondheim NORWAY

ABSTRACT - Background and Objectives: Traditionally, depression among adolescents has been considered uncommon, with around $5 \%$ estimated to suffer from depressive disorder.

The purpose is to investigate occurrence and psychological correlates for depressive symptoms in male and female high school adolescents in urban and rural settings.

Methods: Participants were 1,069 high school students (response rate 92.0\%) with a mean age of 17.6 years. The instruments used were the Zung Depression Self-Rating Scale (SDS), Life Regard Index (LRI), the Neuroticism scale by Eysenck (EPQ-N), the Tension and Effort Stress Inventory (TESI), the Subjective Health Complaints scale (SHC), and the Sense of Humour Questionnaire (SHQ-6).

Results: Analyzes of Variance showed sex and urban/rural main effects, and/or interactions (boys and rural students showing highest positive ratings). Stepwise regression analyzes on depression showed all but the TESI variables to significantly explain $41 \%$ of the variance in depression. The Sense of Humour and Life Regard Index were strong contributors to depression (55\% of variation) when effects of bodily complaints and scores on stressors and efforts were eliminated.

Conclusions: The present study showed an unexpectedly high prevalence of severe $(12.7 \%)$ as well as moderate depressive symptoms (total of $49.2 \%$ ). Therefore, the results indicate an increase of adolescent depression in recent years. Negative and positive mood, as well as sense of humour, goals in life, and fulfilment of goals seemed to be protecting. 
Prevalence of depressive symptoms in adolescents was shown to be higher than expected. Positive resource variables appeared to be protecting.

Received 3 November 2006

Revised 27 April 2008

Accepted 11 July 2008

\section{Introduction}

Traditionally, the school has focused on the academic learning and acquisition of skills, while humanistic care for the student has stayed in the background. Depression in children and adolescents has long been considered rare. A conservative estimate has been that $5 \%$ of adolescents suffer from a depressive disorder, with a dominance of boys in primary school, but hardly any gender difference in adolescence ${ }^{1}$. Lewinsohn et al. showed that risk of major depressive disorder (MDD) is low in childhood, but increases substantially with adolescence ${ }^{2}$. An early account of depressive adolescents suggested treatment in much the same way as for depressive adults ${ }^{3}$. Moreover, depression may present with somatic symptoms. Thus, Larsson investigated the prevalence of somatic complaints among Swedish adolescents aged 13-18 years ${ }^{4}$. Adolescents in the psychiatric group reported more frequent and severe symptoms than those in the other groups.

In the school situation, academic goals should be set, but so should also the improvement of social skills and human relations. Results from a preliminary study indicated a tentative positive effect on academic performance from improving human relations ${ }^{5}$.

The present survey investigated occurrence of depressive symptoms and tentative predictors in adolescents, to better understand their life situation and the role of interaction between psychological and demographic characteristics in prevalence of such depression. Their moods and somatic symptoms as well as their positive resources were also estimated. Specifically, the study aimed at estimating tentative predictive variables for prevalence of depressive symptoms. Instruments to tap different aspects related to depression, beyond a measure of depression itself, included degree of meaningful life, assessment of positive and negative moods, neuroticism, sense of humour, stressors and related efforts invested to cope as well as estimates on the prevalence of a range of bodily complaints. Note that a descriptive account of parts of the present study has been reported elsewhere ${ }^{6}$.

\section{Methods}

\section{Subjects}

Forms with all instruments were distributed to 1,162 students at the high school level, both in the city of Trondheim (urban) and surroundings (rural). The number of completed forms was 1,069 (response rate $92.0 \%$ ). The material consisted of 524 girls and 545 boys $(49 / 51 \%)$ at three class levels, with a mean age of 17.6 (SD 2.5) years.

\section{Instruments}

\section{Depression:}

The Zung self-rating depression scale $(\mathrm{SDS})^{7}$ consists of 20 items, rated on a 4- 
point scale (half 1-4, half 4-1; range scores: 080 ). Scores under 40 are normal, 41-47 indicates light depressive symptoms, 48-55 clear depressive symptoms, and over 55 severe depressive symptoms or depressive disorder.

\section{Meaningful life:}

The Life Regard Index (LRI) ${ }^{8}$ is built on a 28-item questionnaire with two subscales (Goals in life; Fulfilment of goals). Each subscale has 14 items, half phrased positively, and half negatively. The Ss are asked to indicate their own opinion on a 2-point scale (1=disagree, 2 =agree).

\section{Eysenck Personality Questionnaire:}

The 12 items from the Neuroticism subscale of the $\mathrm{EPQ}^{9}$ were used to indicate presence of tension, anxiety and nervousness in everyday life (scored $0=$ no, $1=$ yes) (range 0-12).

\section{Humour:}

The Sense of Humour Questionnaire $(\mathrm{SHQ})^{10}$ has 21 items and three subscales (meta-message sensitivity, social liking of humour, mirthfulness expressed by smiling and laughing), scored on a 4-point scale. In the present study we have used the reduced questionnaire, with only 6 items (SHQ-6) (range 0-18) ${ }^{11}$.

\section{Stressors, efforts and moods:}

The Tension and Effort Stress Inventory $(\text { TESI })^{12}$ has three sections: One addresses the degree of exposure to stressors (pressure, challenge, demand) that one feels exposed to in everyday life (work, family, finance, own body). Another section asks about the degree of effort one puts up to cope with stress within the same areas. The section has five items each with high scores indicating high level of stress or effort. A third section is composed of 8 items on positive mood states, and 8 items on negative mood states. All TESI items are scored on a 7-point scale (1=not at all; 7=very much).

\section{Bodily complaints:}

The Subjective Health Complaints scale (SHC) ${ }^{13}$ includes 27 items on common symptoms of ill health, or bodily complaints. Both intensity $(0=$ no pain, $3=$ severe pain $)$ and duration (0-30 days last month) is scored.

\section{Statistics}

In addition to descriptive statistics, ANOVAs (two-factor analyzes of variance) were computed for all variables, with the gender and rural/urban factors as independent variables, to look for differences and interactions. Although the independent variables were binary, the proportion of subjects in each category was quite balanced, making ANOVA analyzes quite robust. Regression analyzes were computed (stepwise and hierarchical) with depressive symptoms as the dependent variable, and a series of other variables as independent variables.

\section{Results}

\section{Depressive symptoms}

With the Zung self-rating depression scale, most of the subjects fell in the normal (nondepressed) area, whereas $36.5 \%$ could be described as displaying a mild to moderate depressive symptom level, and about $12.7 \%$ scored in the range that indicates a severe depressive symptom level. There were more depressive symptoms in the urban subjects than in the rural ones $(\mathrm{p}<.001)$, and girls scored higher on depression than boys $(\mathrm{p}<.001)$. There was no interaction between these main factors. 


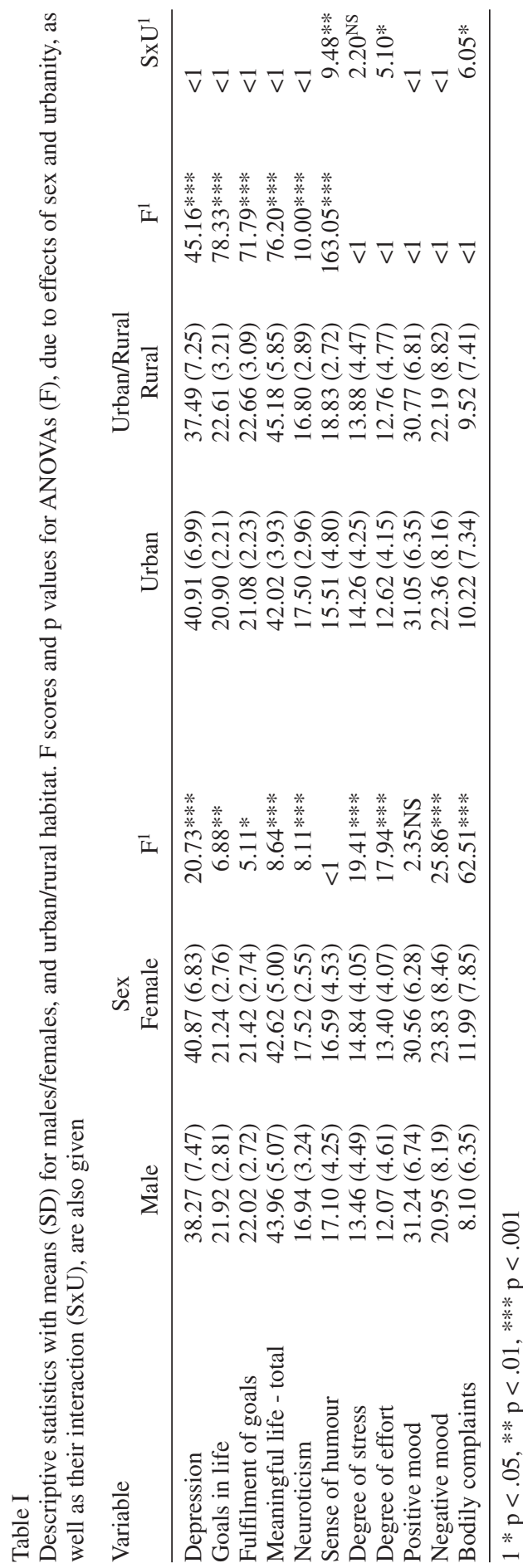

\section{Meaningful life}

The Life Regard Index gives results with the two subscales Goals in life, and Fulfilment of goals (see Table I). There was a clear difference between the respondents in rural and urban districts: Urban youth reported a lower degree of meaningful life than the rural ones according to both variables $(\mathrm{p}<.001)$. There was also a difference between the sexes, with higher scores in the males than in the females on Goals in life $(\mathrm{p}<.01)$ as well as Fulfilment of goals $(\mathrm{p}<.05)$. There was no interaction between the gender and the urban-rural factors.

\section{Eysenck Personality Questionnaire}

On the Neuroticism scale of the survey (EPQ-N), most of the students scored medium high, and few scored in the very high or very low ranges. The urban subjects scored higher than the rural ones $(\mathrm{p}<.001)$, and girls scored higher than boys $(\mathrm{p}<.001)$. There was no interaction between the main factors.

\section{Humour}

With the Sense of Humour Questionnaire (SHQ-6), rural subject yielded higher scores than urban ones $(\mathrm{p}<.001)$, whereas there was no main effect of gender. There was, however, an interaction between the main effects, with the rural boys scoring highest, and the urban girls scoring lowest $(\mathrm{p}<.01$ : see Table I).

\section{Stress and related efforts}

Scores on the Tension and Effort Stress Inventory, subscales on exposure to stres- 
sors and related efforts to cope, yielded no urban/rural main effect for any of the two sets of variables, and girls scored higher than boys $(p<.001)$. In scores on efforts invested to cope with stressors there was an interaction, giving rural girls highest, and urban boys lowest scores $(\mathrm{p}<.05)$.

\section{Mood}

Generally, there was a higher degree of positive mood, compared to negative mood, in the respondents. Only the negative mood variable was significant, with the girls reporting more negative moods "over the last thirty days" than did the boys $(\mathrm{p}<.001)$. The strongest contributors to this difference were scores on the items of anger, sullenness and guilt.

\section{Bodily complaints}

In the Subjective Health Complaints (SHC) scale, most of the students reported little or no bodily complaints and only a few reported complaints to a substantial degree. The most prevalent types of complaints were pain in arms and legs, pain in neck, shoulder and back, headache and sleeping problems. The ANOVA results showed no urban/rural main effect. The sum score of complaints was higher in the girls than in the boys ( $\mathrm{p}<.001)$, and the two ANOVA factors interacted because urban girls scored highest and rural males scored lowest $(\mathrm{p}<.05$ : see Table I).

\section{Correlations}

Correlations were computed between scores on all main sum variables. Many variables reached significance in this large sample, while we will only further discuss corre- lations above .40. Two expected correlations were between fulfilment of goals and goals in life (.67) (two parts of the same questionnaire), as well as degrees of stress and degree of related efforts (.71) (two parts of the same questionnaire). Interestingly, correlations were negative between depression on one side and sense of humour (-.42) as well as meaningful life (-.43) on the other.

\section{Regression analyzes}

In stepwise regression analyzes, with depression as the dependent variable (Table II), seven of the other main variables explained significant proportions of the variance, adding up to the sum of $40.6 \%$. In the hierarchical approach we defined bodily complaints (which only contributed $4.2 \%$ of the depression variance), degree of exposure to stressors, and degree of related efforts as «external noise variables» that were eliminated in step 1 (see Table III). In step 2, the rest of the variables were introduced in the regression analyses. In this way, explained variance in depression increased by $43 \%$ and yielded a cumulated score of $55 \%$. Results stated that sense of humour, meaningfulness in life, negative mood, and positive mood significantly contributed to the overall variance in depression scores. All these psychological variables moderated risk of depression, except negative mood that significantly increased depression scores. Neuroticism did not reach significance in this regression model.

\section{Discussion}

In the present study, according to scores on the Zung self-rating depression scale, $12.7 \%$ of the students yielded scores that indicated severe depressive symptoms, whereas an 
Table II

Stepwise regression analysis for all variables with depression as the dependent variable. Regression $\mathrm{F}$ value increments, $p$ values, $r$ squared, cumulative explained variance, and Beta values are given

\begin{tabular}{llccccr}
$\begin{array}{l}\text { Dependent } \\
\text { variable }\end{array}$ & $\begin{array}{l}\text { Independent } \\
\text { variables }\end{array}$ & $\begin{array}{c}\mathrm{R}^{2} \\
\text { change }\end{array}$ & $\begin{array}{c}\text { Cum } \\
\mathrm{R}^{2}\end{array}$ & $\begin{array}{c}\text { F value } \\
\text { increment }\end{array}$ & p value & Beta \\
\hline Depression & Fulfilment of goals & .19 & .19 & 153.51 & .0000 & -.44 \\
& Sense of humour & .10 & .29 & 95.73 & .0000 & -.33 \\
& Bodily complaints & .06 & .35 & 58.18 & .0000 & .24 \\
& Negative mood & .02 & .38 & 25.58 & .0000 & .17 \\
& Goals in life & .01 & .39 & 14.38 & .0002 & -.16 \\
& Positive mood & .01 & .40 & 10.86 & .0010 & -.10 \\
& Neuroticism & .01 & .41 & 5.88 & .0156 & -.08 \\
& Degree of stress & & & $<1$ & NS & .05 \\
& Degree of effort & & & $<1$ & NS & .04 \\
\hline
\end{tabular}

Table III

Hierarchical regressions with main variables after extracting the variance explained by the «noise variables» bodily complaints, stress, and effort. Depression is used as the dependent variable. Regression F values, $\mathrm{p}$ values, $\mathrm{r}$ squared and Beta values are given

\begin{tabular}{|c|c|c|c|c|c|c|c|}
\hline $\begin{array}{l}\text { Dependent } \\
\text { variable }\end{array}$ & Step & $\begin{array}{l}\text { Independent } \\
\text { variable }\end{array}$ & $\begin{array}{c}\mathrm{R}^{2} \\
\text { change }\end{array}$ & $\begin{array}{c}\text { Cum } \\
\mathrm{R}^{2}\end{array}$ & $\begin{array}{l}\text { F value } \\
\text { increment }\end{array}$ & $\mathrm{p}$ value & Beta \\
\hline \multicolumn{8}{|l|}{ Depression } \\
\hline & I & Bodily complaints & .08 & .08 & 74.36 & .0000 & .29 \\
\hline & & Degree of stress & .04 & .12 & 33.56 & .0000 & .11 \\
\hline & & Degree of effort & & & $<1$ & & -.06 \\
\hline & II & Sense of humour & .16 & .28 & 184.60 & .0000 & -.40 \\
\hline & III & Fulfillment of goals & .13 & .40 & 123.08 & .0000 & -.36 \\
\hline & IV & Goals in life & .13 & .53 & 122.93 & .0000 & -.36 \\
\hline & $\mathrm{V}$ & Negative mood & .04 & .54 & 38.10 & .0000 & .22 \\
\hline & VI & Positive mood & .01 & .55 & 13.25 & .0003 & -.12 \\
\hline & VII & Neuroticism & & & $<1$ & -.01 & \\
\hline
\end{tabular}

additional $36.5 \%$ obtained scores that indicated slight to moderate depressive symptoms. This result suggests a relatively high prevalence of depressive problems in our adolescent population. Females scored higher than males, and urban adolescents scored higher than adolescents living in rural areas. These results confirm those reported from other recent studies, with a trend of increasing prevalence of adolescent depression in normal samples. The gender difference has been attributed to the tendency for girls to respond more strongly to peer events than do boys ${ }^{14}$.
In one study of the validity of a survey measure of depression among adolescents, $10.3 \%(\mathrm{~N}=2300)$ were clinically assessed as obtaining high values in a subsequent diagnostic interview, and males and females were assessed with equal frequencies of depression $^{15}$. Another recent report suggested 7\% of the adolescents to be in the $95 \%$ confidence range $(\mathrm{N}=524)$, with females revealing a higher prevalence for depression than did males ${ }^{16}$. In a somewhat older Scandinavian study ${ }^{17}, 10 \%$ of adolescents were estimated to present with symptoms of depression. The 
latter study did not include a clinical interview for the assessment of depression as a validating reference. It may be wise to keep in mind that assessment of depression by self-rating may not survive a structured clinical interview. However, in the present study, the Zung self-rating scale offers criteria for scores that have been proven to distinguish a normal range of scores from those indicating mild to moderate as well as severe clinical depression ${ }^{7}$. The present findings of a high prevalence of adolescent depressive symptoms are in concert with findings from the extensive Oregon study ${ }^{2}$ that reported 24\% of the participants to suffer from at least one current or previous episode of MDD (Major Depressive Disorder).

In the present study, a number of psychological variables presented as candidates for being contributing variables in depressive symptoms. These variables included sense of humour, goals in life, fulfilment of goals, as well as negative and positive moods. And they appear to explain more than $40 \%$ of the variance in depressive symptoms among high school students. The findings emerged in the stepwise as well as hierarchical approaches to multiple regression analyses. In sum, these psychological variables reflect the importance of resources to cope with more or less opportunistic challenges in adolescent life. Bodily complaints may be transient and due to opportunistic diseases, and sometimes they may represent more enduring, if not genetic dispositions. The availability of personal and social resources to cope with such challenges appeared to strongly influence their potential for causing depressive symptoms. Accordingly, the positive resource variables in the present study (sense of humour, goals in life, fulfilment of goals) came out as being most strongly associated with (lack of) depression. Inability to pursue goals, as reflected in impulsivity, was recently reported to be a significant factor in depression among secondary school students ${ }^{18}$, and regulation strategies mediated this relationship. In the present sample, relatively low scores were found among the urban sub-sample of adolescents for the "protecting" variables, whereas depression was more prevalent among the urban students than among rural ones. It is possible that these associations reflect causal effects due to, on average, a more personal and supportive social network among the rural students, compared with those living in the urban area. Also, the everyday life of the urban adolescent is likely to involve a more chaotic exposure to strangers, commercially oriented temptations as well as a to a diversity of social value systems, compared with exposure to a more uniform and less chaotic everyday life among those living in a rural setting.

For sense of humour, specifically, it is thought compelling to note its strong negative association with depression. The core of sense of humour can be seen as a cognitive coping skill as well as an orientation to the importance of establishing and maintaining social relations, more than as a reflection of positive mood ${ }^{10,19}$. The moderating effect of sense of humour upon the relation between stressors and bodily complaints as well as negative mood has been reported in several studies ${ }^{19}$. Very recently, sense of humour has proven to be a significant factor for twoyear survival among patients coping with end-stage renal failure ${ }^{20}$. However, there was no indication of a strong correlation between depressive symptoms and bodily complaints in the present study, probably due to very low prevalence scores in this cohort $^{5,6}$. Bodily complaints explained $8 \%$ of the variance in depression (see Table III).

Depression is described by a more extensive set of attributes than just the negative mood component. In this light, therefore, the present data are tentatively supportive to 
a role for sense of humour, in conjunction with the experience of meaningfulness in life, as moderators of risk factors involved in the complex process of depressive development. In this process, positive mood came out as a potential moderator, whereas negative mood appeared as a candidate for boosting depressive symptoms (see Table III). Our finding that sense of humour may mitigate depression is in conjunction with findings reported by Porterfield ${ }^{21}$ for undergraduate students. Moreover, the present findings support the conclusion that more personality characteristics than those reflected in sense of humour are involved in this mitigating process.

In a recent study ${ }^{22}$, a very high incidence of recurrence of depression was reported among 274 teenage depressives re-investigated after their $24^{\text {th }}$ year of age. Only one of four was free of illness, and teenage depression gave a substantially elevated risk for later depressive episodes. A comment to that study ${ }^{23}$ pointed at the window of "missed" opportunities that may be experienced by depressed adolescents and to the importance of re-opening through therapy to prevent death in adolescence and young adulthood. Further work should define the extent of that window opportunity and its role in timely and effective prevention as well as treatment of adolescent depression. The present research suggests an important role for positive coping resources in this work.

\section{Conclusion}

The present results showed that approximately half of the adolescents had depressive symptoms (slight/moderate: $36.5 \%$; severe: $12.7 \%$ ). Thus, the prevalence of adolescent depressive symptoms appeared to be higher than traditionally thought of, and this elevated prevalence may reflect a fairly monotonous increase over the recent years. However, these results may be attenuated when a psychiatric interview is performed, rather than assessing depression by the use of a survey scale. Scores on several of the scales included in the present study were inversely related to scores on depression. These variables (sense of humour, goals in life, fulfilment of goals) may therefore indicate psychological resources that mitigate depressive disorder and, therefore, appeared as candidates for protecting resources.

\section{References}

1. Clarke G, Lewinsohn PM, Hops H. Adolescent Coping with Depression Course. Eugene OR: Caste Publ Co; 1990.

2. Lewinsohn PM, Clarke GN, Seeley JR, Rohde P. Major depression in community adolescents. Age at onset, episode duration, and time to recurrence. J Am Acad Child Adolesc Psychiatry 1994; 33: 809-818.

3. Harrington R, Fudge H, Rutter ML, Bredenkamp D, Groothues C, Pridham J. Child and adult depression: a test of continuities with data from a family study. Br J Psychiatry 1993 ; 162: 627-633.

4. Larsson B. Somatic complaints and their relationship to depressive symptoms in Swedish adolescents. J Child Psychol Psychiatry 1991; 32: 821-832.

5. Jensen EN, Götestam KG. The teachers role in improving human relations in high school. A quasi-experimental study. Eur J Psychiat 1998; 12: 5-11.

6. Jensen EN, Svebak S, Götestam KG. A descriptive study of personality, health and stress in high-school students (16-19 years old). Eur J Psychiatry 2004; 18: 153162.

7. Zung WWK, Richards CB, Short MJ. Self-rating depression scale in an outpatient clinic. Arch Gen Psychiatry $1965 ; 13: 508-515$.

8. Battista J, Almond R. The development of meaning in life. Psychiatry 1973; 36: 409-407. 
9. Eysenck HJ, Eysenck SBG, Barrett P. A revised version of the psychoticism scale. Pers Individ Dif 1985; 6: 21-29.

10. Svebak S. Revised questionnaire on the sense of humour. Scand J Psychol 1974; 15: 328-331.

11. Svebak S. The development of the Sense of Humour Questionnaire: from SHQ to SHQ-6. Int J Humour Res 1996; 9: 341-361.

12. Svebak S. The development of the Tension and Effort Stress Inventory (TESI). In: Kerr JH, Murgatroyd S, Apter MJ (Eds.). Advances in reversal theory. Amsterdam: Zwets \& Zeitlinger; 1993. p. 189-204.

13. Ursin H, Endresen IM, Ursin G. Psychological factors and self-reports of muscle pain. Eur J Appl Physiol 1988; 57: 282-290.

14. Hankin BL, Mermelstein R, Roesch L. Sex differences in adolescent depression: Stress exposure and reactivity models. Am J Psychiatry 2007; 78: 279-295.

15. Olsson G, von Knorring AL. Depression among Swedish adolescents measured by the self-rating scale Center for Epidemiologic Studies - Depression Child (CES-DC). Eur Child Adolesc Psychiatry 1997; 6: 81-87.

16 Ivarsson T, Gillberg C. Depressive symptoms in Swedish adolescents: normative data using the Birleson Depression Self-Rating Scale (DSRS). J Affect Disord 1997; 42: 59-68.

17. Larsson B, Melin L. Depressive symptoms in Swedish adolescents. J Abnorm Child Psychol 1990; 18: 91103.

18. d'Acremont M, Van der Linden M. How is impulsivity related to depression in adolescence? Evidence for a
French validation of the cognitive emotion regulation questionnaire. J Adolesc 2007; 30: 271-282.

19. Svebak S, Martin RA. Humour as a form of coping. In: Svebak S, Apter MJ (Eds). Stress and Health: A Revertal Theory Perspective. Wash DC: Tylor \& Francis; 1977. p 173-184.

20. Svebak S, Kristoffersen B, Aasarød K. Sense of humour and survival among a county cohort of patients with end-stage renal failure: A two-year prospective study. Int J Psychiatry Med 2006; 36: 269-281.

21. Porterfield AL. Does sense of humour moderate the impact of life stress on psychological and physical wellbeing? J Res Pers 1987; 21: 306-317.

22. Lewinsohn PM, Rohde P, Seeley JR, Klein DN, Gotlib IH. Natural course of adolescent major depressive disorder in a community sample: predictors of recurrence in young adults. Am J Psychiatry 2000; 157: 1584-1591.

23. Martin A, Cohen DJ. Adolescent depression: window of (missed?) opportunity. Am J Psychiatry 2000; 157: 1549-1551

Address for correspondence:

K Gunnar Götestam

Norwegian University of Science and Technology

Department of Neuroscience

Psychiatry \& Behavioural Medicine

MTFS, NO-7489 Trondheim

Norway

$\mathrm{Ph}+4773864600$

Fax +4773864910

email: gotestam@ntnu.no

\section{Note}

Financial support to this study was given from The Royal Norwegian Ministry of Social Welfare and Health (SHD), Collaborating Board for health promotion (SOHO), The County Municipality of South-Trøndelag, School Division (Trondheim), and the Norwegian University of Science and Technology (NTNU), Trondheim.

The following are gratefully thanked for support, assistance, and participation: Professor Bo Larsson, NTNU; The School Division Director, Ragnhild Engeness, and all students who participated in the study.

A preliminary version of the study was presented at the $6^{\text {th }}$ International Congress of Behavioral Medicine, Brisbane, Australia, November 2000. 


\section{Linguistics \& Language Behavior Abstracts}

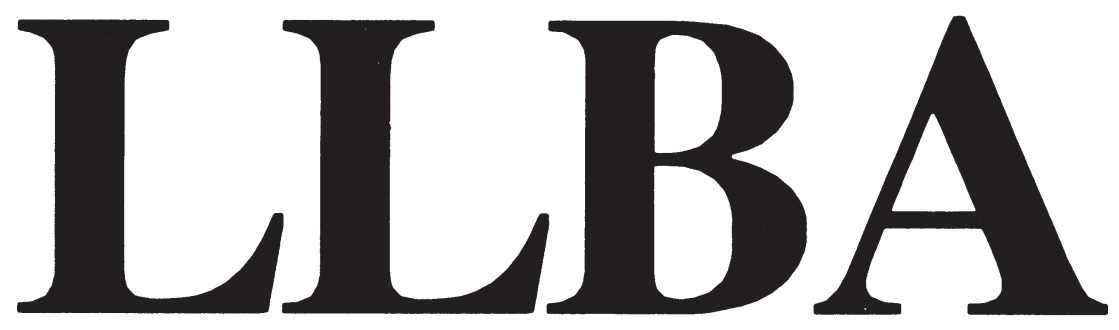

Now entering our 26 th year $(135,000$ abstracts to date) of senvice to linguists and language researchers worldwide. LLBA is available in print and also online from BRS and Dialog.

Linguistics \& Language Behavior Abstracts

$$
\text { P.O. Box } 22206
$$

San Diego, CA 92192-0206

Phone (619) 695-8803 FAX (619) 695-0416

Fast, economical document delivery available. 